\title{
INTERACTION IN ARGUMENTATIVE ESSAYS: THE CASE OF ENGAGEMENT
}

\author{
Hesamoddin Shahriari \\ Farzaneh Shadloo
}

\begin{abstract}
Given the importance of interaction in academic discourse, researchers have investigated the use of stance and engagement markers in written academic texts. However, few of these studies have analyzed engagement features in a register such as the argumentative essay. Employing Hyland's (2001b) engagement framework, this paper examined the use of five engagement markers in a corpus of argumentative essays written by EFL learners across three levels of essay quality. All features of engagement were manually coded and normalized and a one-way ANOVA was subsequently run for analyzing the frequency counts. The findings showed a disassociation between the presence of engagement markers and the overall quality of EFL learners' essays. The current study offers insight into the interactional nature of argumentative essays. We conclude with a discussion of some of the implications so that educators may provide EFL learners with more adequate support in order to write in a more persuasive way.
\end{abstract}

\section{Keywords}

engagement markers, corpus study, EFL learners, argumentative essays, interaction

\section{Introduction}

As persuasion is the principal aim of writing an argumentative essay, establishing a good rapport with readers is considered useful in this regard. This "reader-oriented aspect of interaction which concerns the degree of rapport which holds between communicative participants" (Hyland \& Jiang 2016: 29) is referred to as engagement. This dimension of interaction has been defined by Hyland (ibid.) as the "way that writers explicitly acknowledge the presence of their readers in a text, drawing them in through reader mention, personal asides, appeals to shared knowledge, questions and directives". Concerning the interactional side of written texts, Thompson (2001) noted that a text can be considered as a kind of a conversation between the writer and the reader. This view leads to "seeing the texts not just as constructed with the readers' needs in mind, but as jointly constructed, with communicative space being left for the readers to contribute to the achievement of the text's goals" (Thompson 2001: 62). Hyland (2009: 126) also suggested that engagement is a prominent feature 
of many kinds of argument as "we need to encourage our audience to at least continue reading, if not accept what we have to say". He further pointed out that "in presenting their work, writers must also adopt interactional and evaluative positions, anticipating readers' expectations and responses to participate in what amounts to a virtual dialogue with them" (Hyland 2009: 111).

However, more attention has been drawn to features related to stance "the ways that writers intrude to stamp their personal authority onto their arguments" (Hyland 2005a: 176) than features of engagement despite their functional significance. Similarly, Hyland (2001b) pointed out that in examining the writer-reader interactions, analyzing writer-oriented features can be more informative. Moreover, from among those studies that have been conducted into this domain, most have concentrated on registers such as political, media, or journalism discourse (Hyland 2005a), and few attempts have been made to investigate the use of these audience markers in argumentative essays a sub-register of academic writing - in which persuasion is a key element.

Given the importance of these markers, the current study aims to explore the use of engagement features in the register of argumentative essays written by EFL learners across three levels of writing quality. This study is therefore a contribution to the literature as few studies have attempted to investigate the use of these markers of engagement in learner writing focusing on how they may possibly be linked to judgments of essay quality.

\section{Review of related literature}

\subsection{Interaction in academic writing}

Hyland and Tse (2004) have presented a model of academic metadiscourse, which makes reference to interactive and interactional resources. Interactive resources "refer to features which set out an argument to explicitly establish the writer's preferred interpretations" (Hyland \& Tse 2004: 168). These features, which are about the ways a discourse is organized, include transitions, frame markers, endophoric markers, evidentials, and code glosses (Hyland \& Tse 2004). On the other hand, interactional resources "involve readers in the argument by alerting them to the author's perspective towards both propositional information and readers themselves" (Hyland \& Tse 2004: 168). The latter group of features, which according to Hyland and Tse (2004) are related to the tenor of a discourse, incorporate hedges, boosters, attitude markers, self-mentions and engagement markers, which have been widely investigated in the literature (e.g. Biber \& Finegan 1989, Silver 2003, Biber 2006, Aull \& Lancaster 2014); however, recent studies that have examined the use of engagement features point to the importance of these markers in academic prose especially if we consider 
the writing process as a 'social act'. Similarly, Hyland (2005b: 375) has noted that these interactional features of engagement are not just optional attributes to "be brushed up when students have gained control of other skills, but as central to academic argument: the means by which we encourage our readers to continue reading and, with luck, accept what we have to say". There is also a study into spoken genre by Afshar Mameghani and Ebrahimi (2017) in which they analyzed a corpus of presentations by native English students and they found that engagement features, especially reader pronouns, are more found in the presentation of students than attitude markers. Thus, the authors concluded that it is a matter of importance for speakers to engage their listeners while they are making a presentation.

\subsection{Engagement features}

Engagement features in particular have been the subject of investigations into various types of discourse. Hyland (2001b) examined 240 research articles across eight disciplines in order to learn more about the interactional aspect of academic writing. The results of his study revealed the significance of reader engagement in academic arguments and also how the "discoursal preferences of disciplinary communities rhetorically construct readers" Hyland (2001b: 249). Hyland (2005a: 182) referred to two major aims for utilizing engagement features. The first aim is to "adequately meet readers' expectations of inclusion and disciplinary solidarity ... [and secondly] ... to rhetorically position the audience". The first aim can be fulfilled by the use of reader pronouns and interjections and the second aim can be accomplished by the use of directives, questions, and appeals to shared knowledge (Hyland 2005a).

To provide more details about these markers, Table 1 presents the five main features of engagement. The definitions are the ones used in Hyland's (2005a) study and examples are taken from Hyland (2001b).

\begin{tabular}{|l|l|l|}
\hline Features & Definition & Examples \\
\hline $\begin{array}{l}\text { Reader } \\
\text { pronouns }\end{array}$ & $\begin{array}{l}\text { bringing readers into a discourse, } \\
\text { normally through second person } \\
\text { pronouns }\end{array}$ & $\begin{array}{l}\text { We would expect that over time, plant } \\
\text { genotypes that maximize mycorrhizal } \\
\text { benefits would be at a selective } \\
\text { advantage. }\end{array}$ \\
\hline Questions & $\begin{array}{l}\text { addressing the reader as someone with } \\
\text { an interest in the issue }\end{array}$ & How can these findings be reconciled? \\
\hline
\end{tabular}




\begin{tabular}{|l|l|l|}
\hline Features & Definition & Examples \\
\hline $\begin{array}{l}\text { Appeals } \\
\text { to shared } \\
\text { knowledge }\end{array}$ & $\begin{array}{l}\text { explicit signals asking readers to } \\
\text { recognize something as familiar or } \\
\text { accepted }\end{array}$ & $\begin{array}{l}\text { It should be obvious that very } \\
\text { cognitively disabled people do not, and } \\
\text { cannot, constitute a social-historical } \\
\text { force in the sense I intend. }\end{array}$ \\
\hline Directives & $\begin{array}{l}\text { instructions to the reader, mainly } \\
\text { expressed through imperatives and } \\
\text { obligation modals }\end{array}$ & $\begin{array}{l}\text { Consider now the simple conventional } \\
\text { reflection effect in a magnetic interface. }\end{array}$ \\
\hline $\begin{array}{l}\text { Personal } \\
\text { asides }\end{array}$ & $\begin{array}{l}\text { interrupt the argument to offer a } \\
\text { momment on what has been said, adding }\end{array}$ & $\begin{array}{l}\text { And - as I believe many TESOL } \\
\text { professionals will readily acknowledge } \\
\text { - critical thinking has now begun to } \\
\text { make its mark, particularly in the area } \\
\text { of L2 composition. }\end{array}$ \\
\hline
\end{tabular}

Table 1: Engagement features

Hyland (2005b) analyzed the use of these five engagement features in a corpus of 64 project reports written by Hong Kong undergraduates and then compared the results with a parallel corpus of professional research articles; and he found that students were familiar with "some of the choices available to them but that they see the relationship they need to establish with their readers as relatively limited, constrained by considerations of institutional power, rhetorical confidence and, perhaps, cultural preference" (Hyland 2005b: 375).

In investigating the use of these markers of engagement, some cross-cultural studies were carried out. For instance, Ansarin and Tarlani-Aliabdi (2011) analyzed three sub-corpora including English academic articles written by native English-speaking applied linguists, and academic articles written in English by L1 Persian applied linguists, and articles written in Persian by L1 Persian applied linguists. The findings of their study revealed that more cases of engagement features were found in articles written by L1 English writers compared to both groups of Persian writers. In another study, Lafuente-Millán (2013) investigated the effect of three variables, namely context of publication, language of publication, and national culture on the use of engagement features in three corpora including research articles in the discipline of business management. The first corpus consisted of articles from international journals written by researchers affiliated to English and American universities and the second corpus included articles from international journals written by scholars affiliated to Spanish universities and lastly, the third corpus were articles taken from Spanish journals and the language of publication was also Spanish (Lafuente-Millán 2013). The 
results showed that although the "context of publication has some bearing on the extent to which certain engagement markers are used in RAs, national culture is an even more powerful factor within the multivariate equation which regulates the use of these strategies" (Lafuente-Millán 2013: 219). Marković (2013) examined the use of engagement features in a corpus of introductory textbooks, the results of which implied that reader pronouns, directives, and appeals to shared knowledge are more frequently used in the corpus than questions and personal asides markers.

Other research into this field revolves around the use of engagement features across different sub-registers of academic writing. In this regard, Raoufmoini and Salami (2015) reported a high level of 'interactionality' when they examined stance and engagement markers in a corpus of 280 author guidelines gathered from seven academic publishers. The findings of their study showed extensive use of engagement features. Then the authors noted that "journal editors strategically deploy certain engagement features in author guidelines to address authors explicitly through reader-inclusive pronouns or guide them how to take action through the use of directives" (Raoufmoini \& Salami 2015: 137). Through working with novice writers, Thompson (2001: 58) also showed that "written drafts were improved by exploiting the interactional resources" and he further argued for the "value of raising students" awareness of these resources". In another study, $\mathrm{Fu}$ (2012) carried out an analysis of 220 job postings towards the use of both stance (hedges, boosters, attitude markers and self-mentions) and engagement features (reader-inclusive pronouns, questions and directives) and he concluded that "social distance between the writer and the reader has some link to the employment of interactional metadiscourse resources" (Fu 2012: 413) and when there is a huge gap, the writer tries to make use of more interactional metadiscourse.

Some studies looked into the markers of engagement from a diachronic aspect. For example, Hyland and Jiang (2016) analyzed academic research articles from four disciplines (applied linguistics, biology, electrical engineering and sociology) and across three periods of time (1965, 1985 and 2015). The results of their study revealed that "writers in applied linguistics and sociology substantially reduced their use of engagement [and] biology and electrical engineering authors, on the other hand, have increased their use of engagement, particularly over the last 30 years" (Hyland \& Jiang 2016: 32). In another study, Sahragard and Yazdanpanahi (2017) analyzed the use of these markers in Humanities and Science research articles. They also compared the use of these features across decades of 1990's and 2000's. The results of their study revealed that directives were the most frequent feature in both types of research articles; 
and regarding the two different periods of time, they found a significant difference in both registers throughout the time (Sahragard \& Yazdanpanahi 2017).

By reviewing the studies done into engagement features, an important gap can be identified and that is analyzing these features in the genre of argumentative essays in which persuasion of readers is so central and also investigating how the use of these features may contribute to the effectiveness of argumentative essays. Therefore, this study is an attempt to analyze these markers of engagement in the register of argumentative essays.

\section{Methodology}

\subsection{Material and data collection}

The dataset examined in the current study was a subset of argumentative essays written by Iranian EFL learners. The learners in the study were majoring in English-related studies and the learner's age ranged from 18-30 years. Of the 60 participants in the study, 27 were male and 33 female. The essays were randomly chosen from the Persian sub-corpus of ICLE - the International Corpus of Learner English. The selected argumentative essays were categorized into three levels of quality (higher-rated, mid-rated, and lower-rated essay) through a rating process carried out by three trained raters based on the IELTS writing scoring rubric. Regarding inter-rater reliability, ICC estimates and their 95 per cent confident intervals were calculated using SPSS software (version 23) based on a mean-rating $(k=3)$, absolute-agreement, 2-way mixed-effects model and the 95 per cent confident interval of the ICC estimate showed 0.79-0.89, which is considered as 'good' reliability. As shown in Table 2, the corpus comprised 60 essays amounting to 32,471 words.

\begin{tabular}{|l|c|c|}
\hline Essays & Number of essays & Total number of words \\
\hline Higher-rated essays & 18 & 10,821 \\
\hline Mid-rated essays & 20 & 10,661 \\
\hline Lower-rated essays & 22 & 10,989 \\
\hline
\end{tabular}

Table 2: Details of the corpus

All argumentative essays were written under untimed conditions and learners' consent was obtained by asking them to fill out and sign a Learner Profile Form (see Appendix A). Learners were also asked to provide other information such as the sources they used, their mother tongue and their experience of learning English in the above-mentioned form. The essays were all written in response to the following prompt: 
1. Most university degrees are theoretical and do not prepare students for the real world. They are therefore of little value. Do you agree or disagree with the statement?

2. The prison system is outdated: no civilized society should punish its criminals. It should rehabilitate them. Do you agree or disagree with the statement.

Attempts were made to control variables like genre, timing condition, L1 (all leaners' mother tongue was Persian) for the probable effects these may have on the results as reported in some previous studies (e.g. Lu \& Ai 2015, Lu 2011, Crowhurst 1980).

\subsection{Procedure}

\subsubsection{Coding process}

All the essays were manually coded based on five features of engagement proposed by Hyland (2005a), which include reader mention, questions, appeals to shared knowledge, directives, and personal asides. The coding process was conducted without using word-search tools in order to prevent the inclusion of features such as the exclusive we or non-addressee modals, which should not be considered as engagement markers as they do not address a reader directly.

\subsubsection{Data analysis}

Following the coding process, the frequency of all features was calculated. For analyzing the engagement features, all frequency counts for each essay were normalized to 541 words. This normalization process allows for the use of parametric statistical procedures. Then the data were entered into SPSS software (version 23) and a one-way ANOVA along with Bonferroni post hoc test were run to compare the three groups of essays in terms of their use of engagement markers.

\section{Results and discussion}

In this section, a descriptive analysis of the results is presented in Table 3, which includes the raw and normalized frequency of engagement markers. A total number of 997 markers of engagement were found in the entire corpus. Following this, the results of one-way ANOVA tests, comparing the frequency of these types of markers across essays from three different levels of quality are provided in Table 3. 


\begin{tabular}{|c|c|c|c|c|c|c|}
\hline 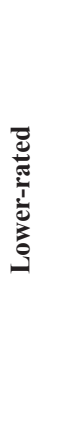 & 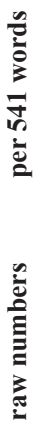 & 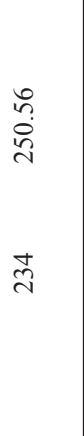 & $\widehat{\imath}$ & $\begin{array}{l}\text { oे } \\
\stackrel{-}{-} \\
\pm\end{array}$ & $\begin{array}{l}\stackrel{g}{\circ} \\
8 \\
8\end{array}$ & $\begin{array}{l}\vec{n} \\
\stackrel{2}{0} \\
\pm\end{array}$ \\
\hline 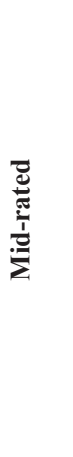 & 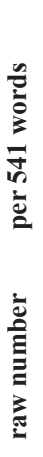 & $\begin{array}{l}\infty \\
\infty \\
\infty \\
\infty \\
-1 \\
\infty \\
\infty\end{array}$ & 9 & $\begin{array}{l}\dot{0} \\
\infty \\
\infty \\
\sim \\
\end{array}$ & 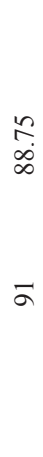 & $\begin{array}{l}\stackrel{n}{r} \\
\infty\end{array}$ \\
\hline 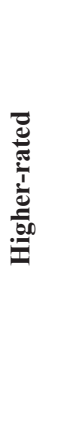 & 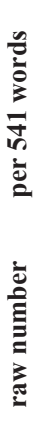 & $\begin{array}{l}\stackrel{+}{2} \\
\stackrel{+}{2} \\
\stackrel{2}{\simeq}\end{array}$ & $\stackrel{\circ}{\circ}$ & ป & $\begin{array}{l}n \\
\tilde{n} \\
\text { nे }\end{array}$ & $\begin{array}{l}\stackrel{2}{\triangleq} \\
=\end{array}$ \\
\hline 苞 & & 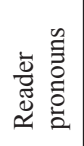 & 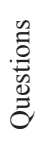 & 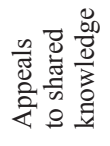 & : & 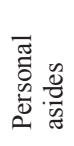 \\
\hline
\end{tabular}


As can be seen from the results obtained, no linear progression was observed in the use of engagement features as the quality of learners' essays improved. The results that are presented in Table 3 show that among the features which were analyzed, reader pronouns were more frequently used in essays compared to other markers of engagement and then directive features were the second most frequent feature. In this regard, $\mathrm{Fu}$ (2012) showed that reader pronouns (194 per 10,000 words) were the most frequent features in the corpus of 220 job postings which were gathered from English-language newspapers and after that directives (19 per 10,000 words) were more commonly used. In a similar vein, Hyland (2008) found that reader pronouns were the most frequent marker observed especially in the disciplines related to soft knowledge areas. Also, Raoufmoini and Salami (2015) illustrated that directives (28 per 1,000 words) and then reader pronouns ( 22 per 1,000 words) were more commonly used in their corpus of 280 journal author guidelines gathered from eight sub-disciplines in the humanities and social sciences. On the other hand, Hyland (2009) found that students underused reader pronouns (6.1 per 10,000 words) in comparison with academic writers who were considered to be experts in their field. Concerning items of reader pronouns, we was the most frequent item in the corpus of the current study. The reason for this high frequency can be that we "claims authority as well as collegiality, helping to guide readers through an argument and towards a preferred interpretation" (Hyland 2008: 18).

The least frequent features in the current study were personal asides and in this regard, Hyland (2009) also reported such an infrequency (0.3 per 10,000 words) in 64 reports written by final year Hong Kong students and then argued that this may be due to the issue that the students were not interested in taking "risks of getting too familiar with a reader whose judgments can have serious consequences for the writer" (Hyland 2009: 126).

The results of one-way ANOVA, as shown in Table 4, indicated no significant differences in the mean values of five features of engagement including reader pronouns $[\mathrm{F}(2,57)=0.69, \mathrm{p}=0.50]$, questions $[\mathrm{F}(2,57)=0.14, \mathrm{p}=0.86]$, appeals to shared knowledge $[\mathrm{F}(2,57)=2.50, \mathrm{p}=0.09]$, directives $[\mathrm{F}(2,57)=$ $0.70, p=0.49]$, and personal asides $[\mathrm{F}(2,57)=1.01, \mathrm{p}=0.36]$ across Iranian EFL learners' argumentative essays. 
Interaction in Argumentative Essays: The Case of Engagement

\begin{tabular}{|l|l|ccc|}
\hline Linguistic Feature & ANOVA Statistics & \multicolumn{3}{|c|}{ Mean Scores (per 541 words) } \\
& & Group 1 & Group 2 & Group 3 \\
\hline Reader pronouns & $\mathrm{F}=0.69 ; \mathrm{P}=0.50>0.05$ & 8.58 & 9.28 & 11.38 \\
\hline Questions & $\mathrm{F}=0.14 ; \mathrm{P}=0.86>0.05$ & 1.06 & 0.95 & 1.23 \\
\hline $\begin{array}{l}\text { Appeals to shared } \\
\text { knowledge }\end{array}$ & $\mathrm{F}=2.50 ; \mathrm{P}=0.91>0.05$ & 1.05 & 1.44 & 0.68 \\
\hline Directives & $\mathrm{F}=0.70 ; \mathrm{P}=0.49>0.05$ & 3.29 & 4.43 & 3.25 \\
\hline Personal asides & $\mathrm{F}=1.01 ; \mathrm{P}=0.36>0.05$ & 0.77 & 0.36 & 0.69 \\
\hline
\end{tabular}

Table 4: Results of one-way ANOVA for engagement features

Based on the results of our study, it can be argued that our EFL learners did not make systematic use of engagement markers in their writing and as the quality of argumentative essays improved, no significant differences were observed in the use of these features. What we found in this study is in line with previous findings which state that covering rhetorical aspects in writing can be a matter of individual difference; so regardless of a learner's level of proficiency, one may prefer to use these features in his/her writing or not. Similarly, Hyland (2001b) noted that patterns of engagement are affected by individual factors like confidence and/or experience.

Another possibility can be cultural issues. According to Hyland and Tse (2004: 175), "the writer's need to supply as many cues as are needed to secure the reader's understanding and acceptance of the propositional content" is closely related to cultural matters. Ansarin and Tarlani-Aliabdi (2011: 157) also mentioned that the "generic constraints on academic prose reflect the cultural habits of the writer's academic community".

It is also likely that our EFL learners did not receive explicit instructions to use engagement markers consciously and strategically in their argumentative essays. Concerning this issue, Ramoroka (2017: 9) noted that students can "benefit more from explicit teaching about the different categories and functions of interactional metadiscourse features available". Vahid Dastjerdi and Shirzad (2010) also referred to the positive effect of explicit instruction of discourse markers on improving Iranian EFL learners' writing.

\section{Conclusion and implications}

By drawing on the Interaction framework, the current study attempted to compare the use of engagement markers in argumentative essays written by a 
group of EFL learners across three levels of writing quality. Our analysis showed no relationship between writing quality and the use of engagement markers. This disassociation between writing quality and engagement markers can be due to the neglecting of some rhetorical features such as the ones we analyzed in the current study by many established scoring criteria and rubrics used for evaluating the quality of written texts. Therefore, we argue that, considering the importance which is ascribed to such features of writing in the existing body of literature, it may be worthwhile to design rubrics for various sub-registers of academic writing by taking into account each register and sub-registers' key elements; for instance, persuasion is a determining factor in argumentative essays, therefore designing a rubric which contains markers of engagement may provide a more careful and realistic assessment of learners' argumentation.

Concerning pedagogical implications, making L2 learners aware of the different kinds of engagement features regardless of their proficiency level can be useful; as it was shown in the study and also some previous studies, reader pronouns and directives were more frequently observed compared to other features. Therefore, teachers are recommended to assist their learners to consider various types of engagement markers in their writing especially in the case of argumentative essays where the persuasion of readers is of paramount importance. In this regard, Thompson (2001: 75) pointed out to the significance of an "explicit attempt to combine discourse analysis with consideration of the training of writing skills". The results of Wingate's (2012) study also revealed that when students enter university, they do not have a clear conception of argumentation and this situation goes from bad to worse since the "instruction they receive at university addresses argumentation inconsistently and insufficiently" (Wingate 2012: 153).

Hence, materials developers are also encouraged to pay more attention to these discourse markers by providing tasks that make learners aware of different engagement markers and their function and how they can make the argumentative essays more persuasive. Also what Hyland (2014) has mentioned can be helpful in this regard that "rhetorical consciousness-raising should involve some kind of focus on texts, and this can be achieved by asking students to conduct mini-analyses of features in the genres they have to write" (Hyland 2014: 356). Therefore, we call on writing instructors to encourage learners to be engaged in reading different samples of argumentative essays and try to find out how discourse markers such as engagement features can add to the power of their argumentation and to see writing as a socially-situated practice.

Concerning the limitations of the study, it would be worthwhile to analyze the use of engagement markers in argumentative essays written by writers from 
different L1 backgrounds. Also, the corpus examined in this study was not a large one due to the time-consuming process of manual coding, so future studies would benefit from examining a larger corpus of essays.

\section{References}

Afshar Mameghani, A. and Ebrahimi, S. F. (2017) 'Realization of attitude and engagement markers in students' presentations.' International Journal of Applied Linguistics \& English Literature 6(2), 73-77. DOI: http://dx.doi.org/10.7575/10.7575/aiac. ijalel.v.6n.2p.73

Ansarin, A. and Tarlani-Aliabdi, H. (2011) 'Reader engagement in English and Persian applied linguistics articles.' English Language Teaching 4(4), 154-164. DOI: http://dx.doi.org/10.5539/elt.v4n4p154

Aull, L. L. and Lancaster, Z. (2014) 'Linguistic markers of stance in early and advanced academic writing: A corpus-based comparison.' Written Communication 31(2), 151-183. DOI: $10.1177 / 0741088314527055$

Biber, D. (2006) University Language: A Corpus-based Study of Spoken and Written Registers. Amsterdam: John Benjamins.

Biber, D. and Finegan, E. (1989) 'Styles of stance in English: Lexical and grammatical marking of evidentiality and affect.' Text-interdisciplinary Journal for the Study of Discourse 9(1), 93-124. DOI: 10.1515/text.1.1989.9.1.93

Crowhurst, M. (1980) 'Syntactic complexity and teachers' quality ratings of narrations and arguments.' Research in the Teaching of English 14(3), 223-231. Retrieved from http://www.jstor.org/stable/40170857

Fu, X. (2012) 'The use of interactional metadiscourse in job postings.' Discourse Studies 14(4), 399-417. DOI: https://doi.org/10.1177/1461445612450373

Hyland, K. (2001b) 'Bringing in the reader: Addressee features in academic writing.' Written Communication 18(4), 549-74. DOI: https://doi.org/10.1177/0741088301018004005

Hyland, K. (2002) 'Options of identity in academic writing.' ELT Journal 56(4), 351-358. DOI: https://doi.org/10.1093/elt/56.4.351

Hyland, K. (2005a) 'Stance and engagement: A model of interaction in academic discourse.' Discourse Studies 7(2), 173-192. DOI: https://doi.org/10.1177/1461445605050365

Hyland, K. (2005b) 'Representing readers in writing: Student and expert practices.' Linguistics and Education 16, 363-377. DOI: 10.1016/j.linged.2006.05.002

Hyland, K. (2008) 'Persuasion, interaction and the construction of knowledge: Representing self and others in research writing.' International Journal of English Studies 8(2), 1-23.

Hyland, K. (2009) 'Corpus informed discourse analysis: The case of academic engagement.' In: Charles, M., Pecorari, D. and Hunston, S. (eds) Academic Writing: At the Interface of Corpus and Discourse. London: Continuum. 110-128.

Hyland, K. and Jiang, F. (2016) "'We must conclude that...": A diachronic study of academic engagement.' Journal of English for Academic Purposes 24, 29-42. DOI: https://doi.org/10.1016/j.jeap.2016.09.003

Hyland, K. and Tse, P. (2004) 'Metadiscourse in academic writing: A reappraisal.' Applied Linguistics 25(2), 156-177. DOI: https://doi.org/10.1093/applin/25.2.156

Lafuente-Millán, E. (2013) 'Reader engagement across cultures, languages and contexts of publication in business research articles.' International Journal of Applied Linguistics 24(2), 201-223. DOI: https://doi.org/10.1111/ijal.12019 
Lu, X. (2011) 'A corpus-based evaluation of syntactic complexity measures as indices of college-level ESL writers' language development.' TESOL Quarterly 45(1), 36-62. DOI: $10.5054 /$ tq. 2011.240859

Lu, X. and Ai, H. (2015) 'Syntactic complexity in college-level English writing: Differences among writers with diverse L1 backgrounds.' Journal of Second Language Writing 29, 16-27. DOI: 10.1016/j.jslw.2015.06.003

Marković, J. (2013) 'Engagement markers in introductory textbooks.' Komunikacija i Kultura Online 4(4), 36-51.

Ramoroka, B. T. (2017) 'The use of interactional metadiscourse features to present a textual voice: A case study of undergraduate writing in two departments at the University of Botswana.' Reading \& Writing - Journal of the Reading Association of South Africa 8(1), 1-11. DOI: https://doi.org/10.4102/rw.v8i1.128

Raoufmoini, R. and Salami, M. (2015) 'Stance and engagement discourse markers in journal's "author guidelines." Journal of Teaching Language Skills 34(3), 109-140. DOI: $10.22099 /$ JTLS.2015.3583

Sahragard, R. and Yazdanpanahi, S. (2017) 'English engagement markers: A comparison of humanities and science journal articles.' Language Art 2(1), 111-130.

Silver, M. (2003) 'The stance of stance: A critical look at ways stance is expressed and modeled in academic discourse.' Journal of English for Academic Purposes 2(4), 359-374. DOI: 10.1016/s1475-1585(03)00051-1

Thompson, G. (2001) 'Interaction in academic writing: Learning to argue with the reader.' Applied Linguistics 22(1), 58-78. DOI: https://doi.org/10.1093/applin/22.1.58

Vahid Dastjerdi, H. and Shirzad, M. (2010) 'The impact of explicit instruction of metadiscourse markers on EFL learners' writing performance.' The Journal of Teaching Language Skills 2(2), 154-174.

Wingate, U. (2012) "Argument!' helping students understand what essay writing is about.' Journal of English for Academic Purposes 11(2), 145-154. DOI: https://doi. org/10.1016/j.jeap.2011.11.001 


\section{Appendix A}

\section{LEARNER PROFILE}

Text code: (do not fill in)

Essay:

Title:

Approximate length required: 0

Conditions: 0

$$
-500 \text { words } 0 \quad+500 \text { words }
$$

timed $\quad 0 \quad$ untimed

Examination: yes $\quad 0$

No 0

Reference tools: $\quad$ yes yes $\quad 0 \quad$ no 0

What reference tools?

Bilingual dictionary:-

English monolingual dictionary:

Grammar:-

Other(s):-

Surname: first names:

Age: Male 0

0

Nationality:

Native language:

Father's mother tongue:

Mother's mother tongue:

Language(s) spoken at home: (if more than one, please give the average $\%$ use of each)

Education:

Primary school - medium of instruction:

Secondary school - medium of instruction:

Current studies:

Current year of study:

Institution:

Medium of instruction:

English only 0

Other language(s) (specify) 0

Both 0

Years of English at school:

Years of English at university:

Stay in an English-speaking country:

Where?

When? How long?

Other foreign languages in decreasing order of proficiency:

I hereby give permission for my essay to be used for research purposes.

Date:

Signature: 
Hesamoddin Shahriari is Assistant Professor of applied linguistics at Ferdowsi University of Mashhad where he teaches undergraduate and graduate-level academic writing. His research interests include academic writing, learner corpora and formulaic language.

Address: Hesamoddin Shahriari, Department of English, Ferdowsi University of Mashhad, Park Square, Mashhad, Iran. [e-mail: h.shahriari@um.ac.ir]

Farzaneh Shadloo is a graduate student in TEFL/Applied Linguistics at Ferdowsi University of Mashhad. Her research interests include corpus linguistics, academic writing, and learner English.

Address: Farzaneh Shadloo, Department of English, Ferdowsi University of Mashhad, Park Square, Mashhad, Iran. [e-mail: Farzaneh.shadloo@yahoo.com] 